\title{
A study of Magnetic Induction Tomography (MIT) for Calcium Oxalate Renal Screening
}

\section{Thompson Paulus ${ }^{a}$, Nur Amira Zulkifllia ${ }^{a}$ Fatin Aliah Phang Abdullah ${ }^{b}$, Azli Yahya ${ }^{a}$, Siti Zarina Abdul Mujic ${ }^{\mathrm{c}}$, Jaysuman Pusppanathan ${ }^{\mathrm{d}, *}$}

a School of Biomedical Engineering and Health Sciences, Faculty of Engineering, Universiti Teknologi Malaysia, 81310 UTM Johor Bahru, Johor, Malaysia; ${ }^{b}$ Centre for Engineering Education (CEE) School of Education, Faculty of Social Sciences \& Humanities, Universiti Teknologi Malaysia, 81310 UTM Johor Bahru, Johor, Malaysia; ${ }^{\mathrm{c}}$ Centre for Environmental Sustainability and Water Security, Universiti Teknologi Malaysia, 81310 UTM Johor Bahru, Johor, Malaysia; Department of Electronic Engineering, Faculty of Electrical and Electronic Engineering, Universiti Tun Hussein Onn Malaysia 86400 Parit Raja, Batu Pahat, Johor, Malaysia; ${ }^{d}$ Sports Innovation \& Technology Centre (SITC), Institute of Human Centered Engineering (iHumEn), Universiti Teknologi Malaysia, 81310 Skudai Johor, Malaysia

Abstract Nephrolithiasis is a process of stone formation in the kidney by crystallization. The increasing prevalence of nephrolithiasis from time to time had sought an alternative from the conventional imaging techniques that is invasive, radiative, and non-rapid usage. This paper enclosed a design simulation study of Magnetic Induction Tomography (MIT) system using COMSOL Multiphysics for renal imaging. MIT is a soft field tomography and non-contact imaging modality which can project the passive electromagnetic properties (conductivity, permittivity and permeability) under the principle of electromagnetic induction. In this research, 8 copper transreceiver coils were employed in the MIT system and fixed by the insulation belt. Meanwhile, geometric set-up of renal organ was set to imitate the transverse section of human renal. In the methodology, sensor performance analyses were done using frequency ranging from $50 \mathrm{kHz}$ to 2 $\mathrm{MHz}$ of the MIT system on radii of calcium oxalate in renal. The sensor response and pattern are discussed in this paper.

Keywords: Magnetic Induction Tomography (MIT), kidney screening, medical imaging, calcium oxalate screening, renal imaging

jaysuman@biomedical.utm. my

Received: 13 April 2021

Accepted: 15 August 2021

(C) Copyright Paulus. This article is distributed under the terms of the Creative Commons Attribution License, which permits unrestricted use and redistribution provided that the original author and source are credited.

\section{Introduction}

Tomography is originally derived from the Greek which brings the meaning of 'slice' or 'section'. The evolution of tomography started as Conrad Röntgen discovered X-ray in 1895. The X-ray was found to be able to project the internal image of human body. Soon after the discovery, the need of tomography in medical line had been given more attention as it offers many advantages [1]. Nephrolithiasis is a formation of stone in the kidney by precipitation or crystallization [2]. In the paper by Sreenevasan, G analyzed, the occurrence of nephrolithiasis in peninsular Malaysia had increased linearly from 1962 to 1981 which is around 225 cases to 425 cases per 100,00 people [3]. It was observed too, that male has higher tendency to develop nephrolithiasis compared to female which is much more related to diet of 
male group which favour more on protein-based diet [3-5]. The increasing prevalence of nephrolithiasis had led to seeking more advanced medical imaging technologies such as Computed Tomography (CT) scanner, ultrasound and Magnetic Resonance Imaging (MRI). However, due to the ionization exposure in CT scanner, its accessibility is limited to pregnant mothers as it will harm the development of the fetus [6]. Meanwhile, the mechanical energy of the wave in an ultrasound device produces heat that gives a thermal effect to patients if being used rapidly for a long time [7]. Magnetic Resonance Imaging (MRI) consumes a longer time for each imaging session to complete and gives a claustrophobic experience to patients [8].

\section{Hardware Components in MIT}

MIT work is based on the theory of mutual induction [9]. It is a soft field tomography and a non-contact imaging modality which projects electromagnetic passive properties conductivity, permittivity, and permeability [10] of material under the influence of eddy current [10-14]. As shown is Figure 1 [14], the basic system of MIT is made up of several main components such as sensors (which includes transmitting coils, receiving coils and screen) [9,15], interface electronics and host computer (which includes software for image reconstruction algorithm) $[10,14]$.

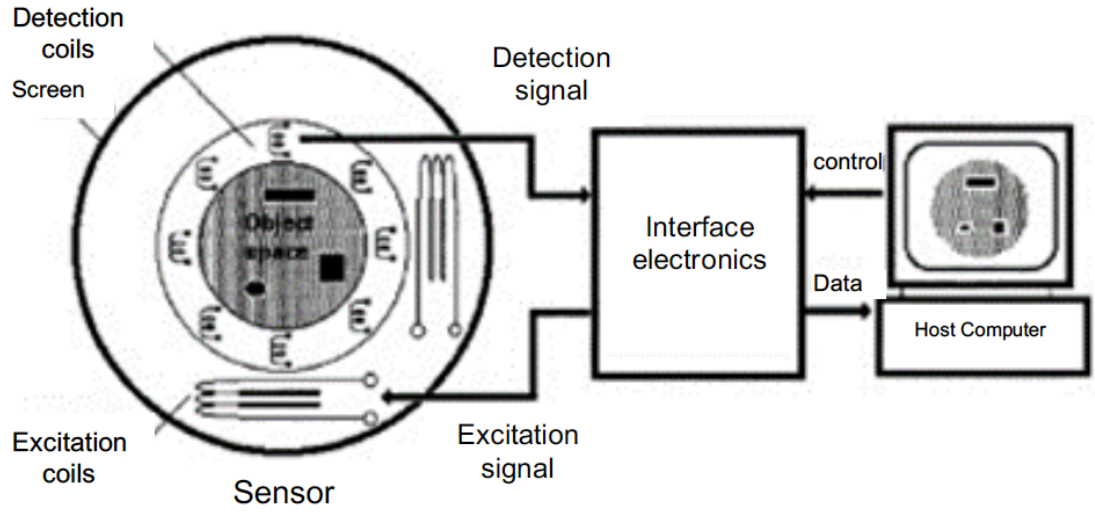

Figure 1. Block Diagram of a typical MIT System [14]

\section{Working Principle of MIT}

The working principle of MIT is illustrated as in Figure 2 [16]. MIT applies primary sinusoidal electromagnetic field $\left(B_{0}\right)$ which are generated by excitation coil [9-12,16-19]. The electromagnetic signal propagates and then penetrates the object which is located in the region of interest (ROI) $[10,12,17,18,20,21]$. At the meantime, eddy currents are induced from within the object itself, due to its conductivity property [9-13,17-21]. Based on Lenz's Law, a secondary magnetic field $(\Delta B)$ is generated by eddy currents which are measured by sensors at the receiving coils [9-13,16-19,22]. The perturbation of secondary magnetic field $(\Delta B)$ contains a real part (due to displacement currents) and an imaginary part (due to impedance) [11]. The density of secondary magnetic field $(\Delta B)$ carries information of electrical properties of that object $[9,17,18,20,22]$. This information will be sent to a computer host for image reconstruction $[17,20]$.

The measurement is divided into two steps. Firstly, MIT measures the ambient air as a reference value, then only it measures the object under test [21,23]. The measurement on the object, results in phase delay as sensitivity of measurement is based on the phase shift approach. The measured potential of primary and secondary magnetic field is represented as $B_{0}$ and $\Delta B$, respectively [21]. The subtraction operation between these two phase value produces an image $[21,23]$.

In biological tissue, MIT is produces image due to the changes in conductivity, as conductivity is dominant 
compared to permittivity and permeability. This working frequency is under the dispersion range of 10 $\mathrm{kHz}-10 \mathrm{MHz}$ [17]. Besides, interaction of an electromagnetic field and biological tissue also is governed by the Maxwell's rules [11,17] which explains that; changes in eddy current field due to conductivity of diseased tissue is reflected in data analysis in recognizing pathology [11].

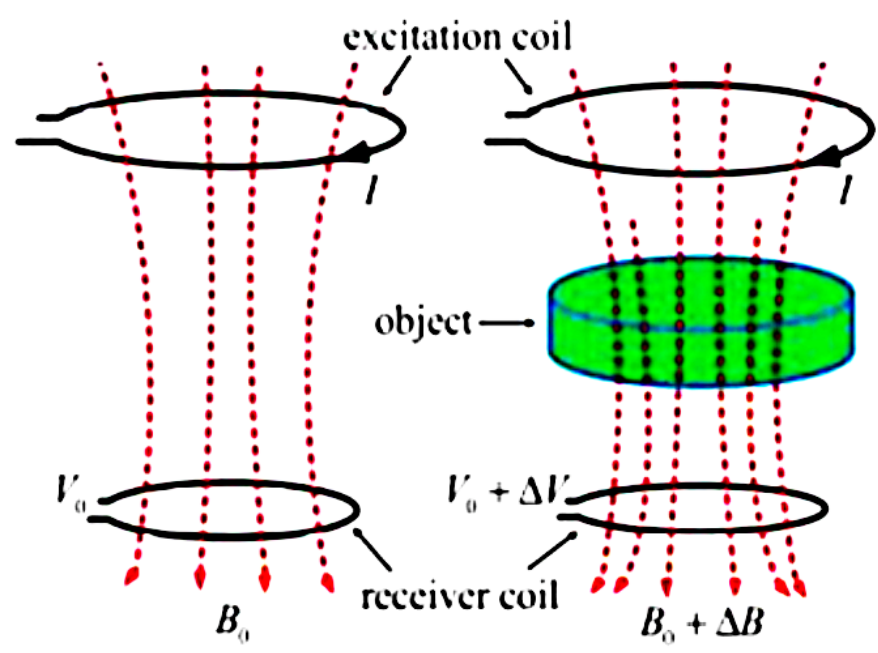

Figure 2. Schematic diagram of working principle of MIT [16]

\section{Equations in MIT Principle}

Maxwell's equation (Faraday's law, Ampere's law and Coloumb's Law) is applied to study the interaction between electromagnetic fields and biological tissues [24]. Based on Equation (1), Faraday's law stated that, by applying time varying magnetic field density, B with frequency $(\omega)$, an electric field $(E)$ is induced $[25,26]$;

$$
\nabla \times \frac{1}{\mu} B=\sigma E+j \omega E+J_{s}
$$

where,

$\mu=$ magnetic permeability

$\mathrm{B}=$ magnetic induction intensity

$\sigma=$ electrical conductivity

$E=$ electric field intensity

$\mathrm{j}=$ imaginary part unit

$\omega=$ angular frequency of excitation source

Js = electric current density

Meanwhile, the induced voltage, $\Delta \mathrm{v}$ at the receiver is calculated using Lenz's law by integrating magnetic field over the receiver coil surfaces, dS as in Equation (2) [17];

$$
\Delta v=-j \omega \int \Delta B \cdot d S
$$

where,

$$
\begin{aligned}
\Delta v & =\text { induced voltage } \\
J & =\text { imaginary part unit } \\
\omega & =\text { angular frequency of excitation source } \\
\Delta B & =\text { secondary magnetic field }
\end{aligned}
$$




\section{Materials and methods}

Figure 3 outlined the flowchart for COMSOL simulation beginning from preprocessing to post-processing result analysis.

Under the 'physics selection', this study employs 'electromagnetism' multiphysic to carry out the fundamentals for the virtual experiment. The next configuration is the 'geometry set-up' for renal organ and MIT sensor configuration for homogeneous and inhomogeneous conditions, shown in Figure 4 and Figure 5, respectively. For both conditions of geometric set-up, the width and height of each copper transreceiver coils are $0.060 \mathrm{~m}$ and $0.025 \mathrm{~m}$, respectively, and embedded surrounding the insulation belt. Each of the eight trans-receiver coils is fixed at $0^{\circ}, 45^{\circ}, 90^{\circ}, 135^{\circ}, 180^{\circ}, 225^{\circ}, 270^{\circ}, 315^{\circ}$, and $360^{\circ}$, respectively, from the center of the MIT system. The dimension of the insulation belt is set as $0.260 \mathrm{~m}$ (asemiaxis) and $0.180 \mathrm{~m}$ (b-semiaxis). The belt is non-contact to reduce noise from the uneven surface of the skin.

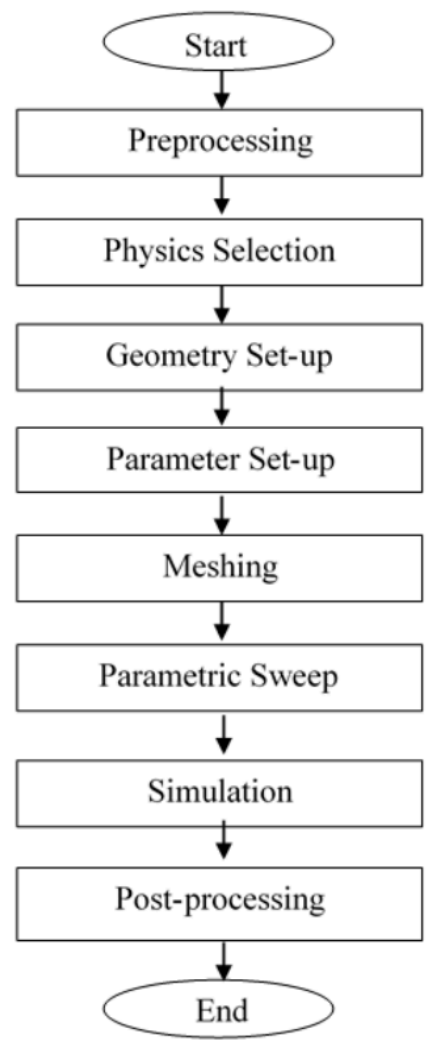

Figure 3. Flowchart of COMSOL Multiphysics simulation

The geometric set-up of the transverse cut of human renal is surrounded by body fluid, as shown in both Figure 4 and Figure 5. Each renal consisted of perirenal fat (outer layer), renal medulla (middle layer) and renal cortex (inner layer) with dimension of $0.065 \mathrm{~m}$ (a-semiaxis) and $0.045 \mathrm{~m}$ (b-semiaxis). The location of the left renal (from the reader's view) was $-0.080 \mathrm{~m}$ and $0.050 \mathrm{~m}$ at the $\mathrm{x}$-axis and $\mathrm{y}$-axis, respectively, with a clockwise rotation of $270^{\circ}$. The location of the right kidney (from the reader's view) is the reflection of the left kidney at line $x=0$, with $30^{\circ}$ of clockwise rotation. Besides, the dimension of the stomach is $0.220 \mathrm{~m}$ and $0.140 \mathrm{~m}$ for a-semiaxis and b-semiaxis, respectively. The surrounding of the MIT system is air. In geometric set-up of inhomogeneous condition, the sizes of calcium oxalate were set up as, $r=0.003 \mathrm{~cm}, 0.006 \mathrm{~cm}, 0.009 \mathrm{~cm}, 0.012 \mathrm{~cm}, 0.015 \mathrm{~cm}, 0.018 \mathrm{~cm}, 0.021 \mathrm{~cm}, 0.024 \mathrm{~cm}, 0.027 \mathrm{~cm}$ and $0.030 \mathrm{~cm}$ respectively throughout the study simulation. 


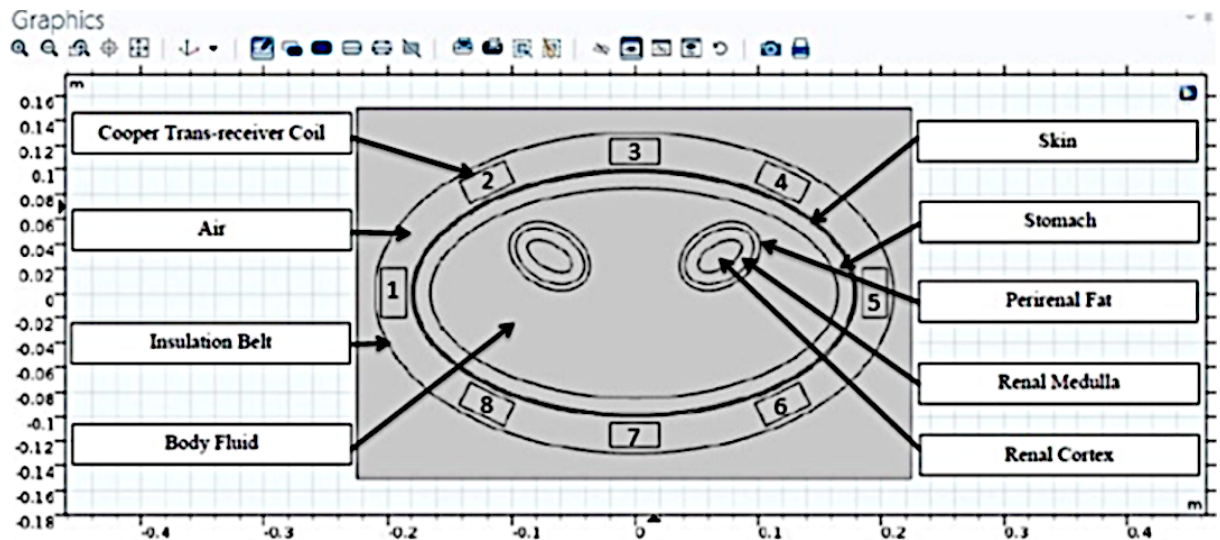

Figure 4. Geometric set-up and sensor configuration of a homogenous condition

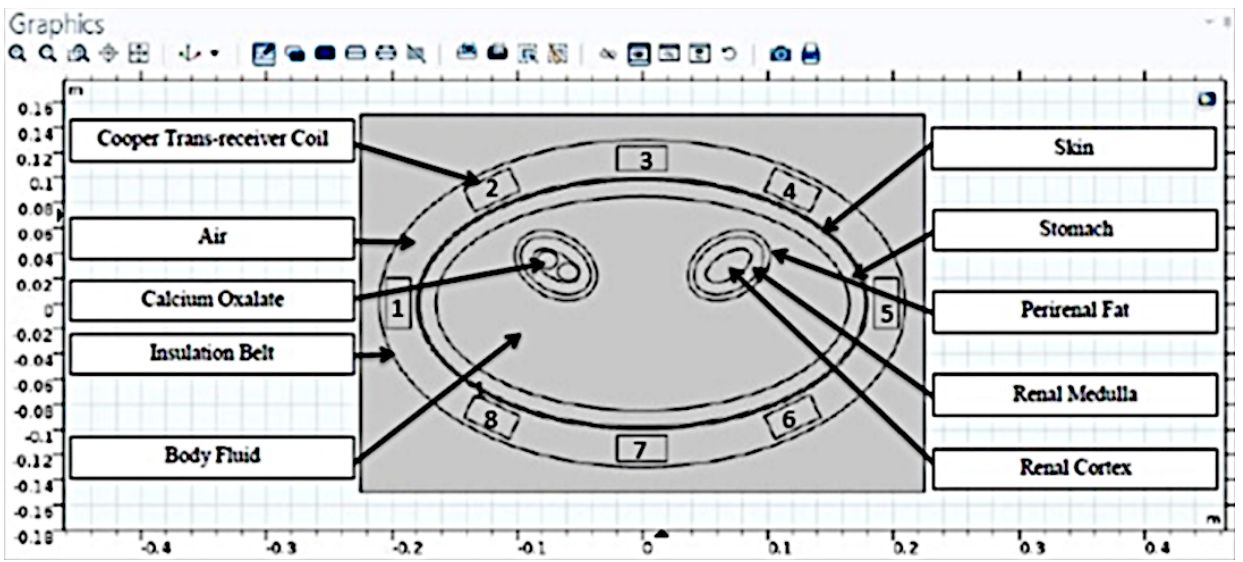

Figure 5. Geometric set-up and sensor configuration of inhomogeneous condition

Table 1 shows the parameter set-up consisting of the values of conductivity, relative permeability, and relative permittivity of materials at $10 \mathrm{kHz}$ of working frequency. The values of Passive Electrical Properties (PEP) are referred, for all material excluding calcium oxalate, from The Foundation for Research on Information Technologies in Society (IT'IS) [27] and the Italian National Research Council [28]. Both values of relative permittivity and relative permeability of materials were calculated based on Equation (3) [29];

$$
\delta=\frac{1}{\sqrt{\pi f \mu \sigma}}
$$

where,

$\delta=$ standard depth of penetration

$\mathrm{f}=$ test frequency

$\mu=$ magnetic permeability

$\sigma=$ electrical conductivity

For calcium oxalate, [30] estimated that the conductivity of calcium oxalate is $7.5 \mu \mathrm{Sm}-1$ at $10000 \mathrm{~Hz}$. After the 'parameter set-up' step completed, 'meshing' step is enabled to fraction the elements into smaller parts. Next, 'parametric sweep' step was done to repeat multiple simulations with different variables. Finally, 'post-processing' analysis is carried out to evaluate the sensitivity performance of each coil. 


\section{Results and discussion}

Simulation study of sensitivity performance of MIT system was executed by exciting one coil at a time, while the remaining coils detect and measure the magnetic flux values. Each coil is in-turn assign to excite and receive magnetic flux to complete a full scan that consists of eight projection cycles. This simulation studied the performance of coil sensor towards various system frequencies, which are $50 \mathrm{kHz}$, $100 \mathrm{kHz}, 500 \mathrm{kHz}, 1000 \mathrm{kHz}, 1.5 \mathrm{MHz}$ and $2 \mathrm{MHz}$. In previous research done by B. Gowry et al. had used system frequency below than $50 \mathrm{kHz}$, which were from $100 \mathrm{~Hz}$ to $10 \mathrm{kHz}$, for tomography of rectum and breast [31]. Biological tissues which are in hydration state, are well reflected by their high conductivity values [32]. In this research, aims to distinguish the presence of calcium oxalate in renal. Different from biological tissue, calcium oxalate has relatively low conductivity value compared to other materials (refer Table 1). High system frequency is required so that the presence of calcium oxalate can be projected in the tomography.

Table 1. Passive electrical properties (PEP) of materials at working frequency of $10 \mathrm{kHz}[27,28]$

\begin{tabular}{cccc}
\hline Type of Material & Conductivity (S/m) & Relative Permittivity & Relative Permeability \\
\hline Air & 0 & 1 & 1 \\
Renal Cortex & 0.13774 & 38748 & 0.855434635 \\
Renal Medulla & 0.13774 & 38748 & 0.855434635 \\
Stomach & 0.52973 & 8698.7 & 0.990639627 \\
Perirenal Fat & 0.02383 & 1085.3 & 0.974741105 \\
Body Fluid & 1.5 & 98.919 & 0.999693244 \\
Skin & 0.00020408 & 1133.6 & 0.157741333 \\
Calcium Oxalate & $\sim 0.0000075$ & $\sim 13$ & $\sim 1$ \\
\hline
\end{tabular}

Table 2 and Figure 6 show the sensitivity value and sensitivity performance at excitation of coil 3 with fixed radius of $0.018 \mathrm{~m}$ calcium oxalate, respectively. Based from Figure 6 , it was observed that coil 4 and coil 2 have the highest sensitivity values compared to other coils. This is due to position of coil 4 and coil 2 which are closest to the excitation coil 3, thus received greatest total magnetic flux without the effect of eddy current. Even though, coil 2 and coil 4 were not located in parallel direction $\left(180^{\circ}\right)$ to the magnetic field, however, high intensity of magnetic fields which was excited from coil 3 were significant for coil 2 and coil 4.

In Figure 6, there was a slight spike in sensitivity value at receiving coil 6 compared to coil 1, coil 5, coil 7 and coil 8 . Meanwhile, the sensitivity value of coil 8 is lower compared to coil 6 , even though both were located at same distance from exciting coil 3. By referring from Figure 5, calcium oxalates were only located at right kidney (left from reader's view). The presence of calcium oxalates had induced greater eddy current, which consequently induced greater secondary magnetic field. The greater secondary magnetic field which is in opposite direction of primary magnetic field produced less total magnetic flux [33]. Coil 5 had lower sensitivity value compared to coil 6 despite its distance which is closer to exciting coil 3. This condition was due to unparalleled direction of magnetic field which was excited from coil 3 to coil 5. Meanwhile, direction of magnetic field which was excited from coil 3 to coil 5 was more parallel. Thus, coil 5 had lower sensitivity value compared to coil 6 . Besides, coil 7 had lower sensitivity value compared to coil 6 despite its parallel direction from coil 3 compared to coil 6 . This was due to eddy current effect. The location of coil 7 was nearer to the location of calcium oxalate compared to coil 6 thus 
it received greater eddy current effect. Received of eddy current led to greater secondary magnetic field and less total magnetic flux [33]. Thus, sensitivity value of coil 7 was lesser compared coil 6.

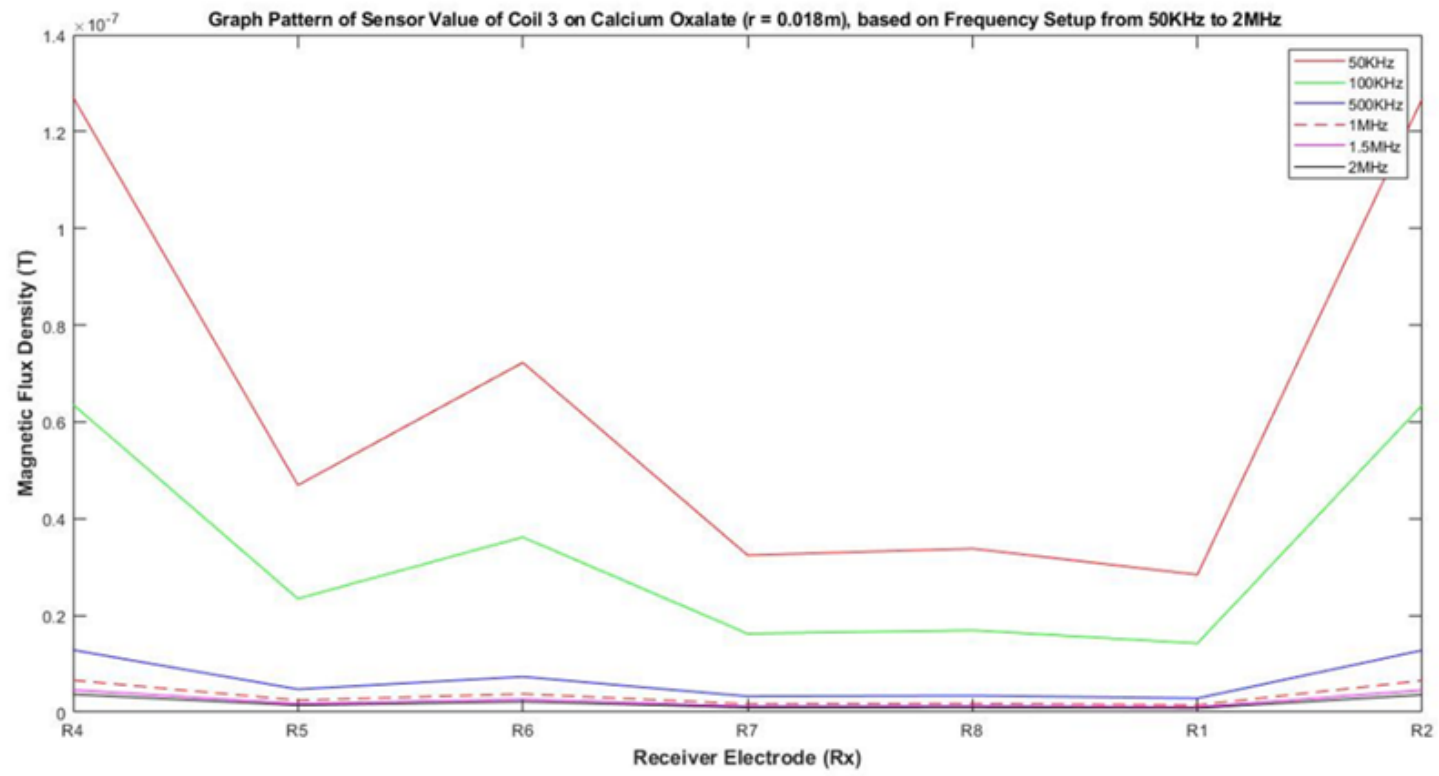

Figure 6. Graph of sensitivity performance at excitation coil 3, with radius of $0.018 \mathrm{~m}$ of calcium oxalate

This simulation also studied the performance of coil sensor towards various radii of calcium oxalate, which is $0.000 \mathrm{~m}, 0.003 \mathrm{~m}, 0.006 \mathrm{~m}, 0.009 \mathrm{~m}, 0.012 \mathrm{~m}, 0.015 \mathrm{~m}, 0.018 \mathrm{~m}, 0.021 \mathrm{~m}, 0.024 \mathrm{~m}, 0.027 \mathrm{~m}$, and $0.030 \mathrm{~m}$. Table 3 and Figure 7 presented the tabulated sensor values of each respective coil at an operating frequency of $1 \mathrm{MHz}$ and the plotted sensor values, respectively. Meanwhile, Figure 8 shows the magnified view of Figure 6, revealing the plotted sensor values for every radius of calcium oxalate. By referring to Figure 7, the differences in sensitivity performances between different sizes are not too significant. However, when the graph was magnified as shown in Figure 8, it was observed that radii of calcium oxalate were inversely proportional to sensitivity performance of coils.

Table 2. Sensitivity values at excitation of coil 3 , with radius of $0.018 \mathrm{~m}$ of calcium oxalate

\begin{tabular}{cccccccc}
\hline Frequency & Coil 4 & Coil 5 & Coil 6 & Coil 7 & Coil 8 & Coil 1 & Coil 2 \\
\hline $50 \mathrm{kHz}$ & $\begin{array}{c}1.2712 \mathrm{E}-07 \\
\text { (log10) }\end{array}$ & $4.6914 \mathrm{E}-08$ & $7.2259 \mathrm{E}-08$ & $3.2425 \mathrm{E}-08$ & $3.3792 \mathrm{E}-08$ & $2.8409 \mathrm{E}-08$ & \\
& & & & & \\
$100 \mathrm{kHz}$ & $6.3600 \mathrm{E}-08$ & $2.3465 \mathrm{E}-08$ & $3.6171 \mathrm{E}-08$ & $1.6219 \mathrm{E}-08$ & $1.6912 \mathrm{E}-08$ & $1.4218 \mathrm{E}-08$ \\
$500 \mathrm{kHz}$ & $1.2824 \mathrm{E}-08$ & $4.7415 \mathrm{E}-09$ & $7.3067 \mathrm{E}-09$ & $3.2716 \mathrm{E}-09$ & $3.4119 \mathrm{E}-09$ & $2.8687 \mathrm{E}-09$ \\
$1 \mathrm{MHz}$ & $6.5780 \mathrm{E}-09$ & $2.4492 \mathrm{E}-09$ & $3.7674 \mathrm{E}-09$ & $1.6803 \mathrm{E}-09$ & $1.7526 \mathrm{E}-09$ & $1.4738 \mathrm{E}-09$ & $1.2781 \mathrm{E}-08$ \\
$1.5 \mathrm{MHz}$ & $4.5824 \mathrm{E}-09$ & $1.7263 \mathrm{E}-09$ & $2.6472 \mathrm{E}-09$ & $1.1729 \mathrm{E}-09$ & $1.2234 \mathrm{E}-09$ & $1.0290 \mathrm{E}-09$ & $4.5137 \mathrm{E}-09$ \\
$2 \mathrm{MHz}$ & $3.6666 \mathrm{E}-09$ & $1.4041 \mathrm{E}-09$ & $2.1437 \mathrm{E}-09$ & $9.4085 \mathrm{E}-10$ & $9.8121 \mathrm{E}-10$ & $8.2547 \mathrm{E}-10$ \\
\hline
\end{tabular}

From Figure 8 also, the sensitivity value was the highest when the radius of calcium oxalate was $0.000 \mathrm{~m}$, while the sensitivity values started to decrease when the radii of calcium oxalate became bigger. Overall, it could be explained that, the presence of calcium oxalate would increase the induction intensity of eddy current, and eventually yielded greater secondary magnetic field which was in opposite direction with primary magnetic field, thus reduced the total magnetic flux. 
Table 3. Sensitivity values at exciting coil 5 under $1 \mathrm{MHz}$ frequency

\begin{tabular}{|c|c|c|c|c|c|c|c|}
\hline Radius & Coil2 & Coil3 & Coil4 & Coil5 & Coil6 & Coil7 & Coil8 \\
\hline 0.000 & 8.3500E-08 & 6.0289E-09 & 4.2464E-09 & 2.8989E-09 & 6.9933E-09 & 8.9008E-09 & 7.1553E-08 \\
\hline 0.003 & 8.3496E-08 & 6.0251E-09 & 4.2446E-09 & 2.8979E-09 & 6.9916E-09 & 8.9001E-09 & 7.1554E-08 \\
\hline 0.006 & 8.3484E-08 & 6.0135E-09 & 4.2394E-09 & 2.8950E-09 & 6.9862E-09 & 8.8980E-09 & 7.1557E-08 \\
\hline 0.009 & 8.3463E-08 & 5.9943E-09 & 4.2307E-09 & 2.8902E-09 & 6.9774E-09 & 8.8946E-09 & 7.1562E-08 \\
\hline 0.012 & 8.3433E-08 & 5.9676E-09 & 4.2186E-09 & 2.8835E-09 & 6.9650E-09 & 8.8898E-09 & 7.1570E-08 \\
\hline 0.015 & 8.3391E-08 & 5.9336E-09 & 4.2031E-09 & 2.8749E-09 & 6.9491E-09 & 8.8836E-09 & 7.1579E-08 \\
\hline 0.018 & 8.3337E-08 & 5.8925E-09 & 4.1845E-09 & 2.8646E-09 & 6.9299E-09 & 8.8759E-09 & 7.1591E-08 \\
\hline 0.021 & 8.3266E-08 & 5.8448E-09 & 4.1627E-09 & 2.8524E-09 & 6.9072E-09 & 8.8668E-09 & 7.1605E-08 \\
\hline 0.024 & 8.3180E-08 & 5.7950E-09 & 4.1396E-09 & 2.8394E-09 & 6.8828E-09 & 8.8567E-09 & 7.1621E-08 \\
\hline 0.027 & 8.3074E-08 & 5.7484E-09 & 4.1172E-09 & 2.8266E-09 & 6.8584E-09 & 8.8458E-09 & 7.1637E-08 \\
\hline 0.030 & 8.2944E-08 & 5.7025E-09 & 4.0943E-09 & 2.8134E-09 & 6.8329E-09 & 8.8340E-09 & 7.1653E-08 \\
\hline
\end{tabular}

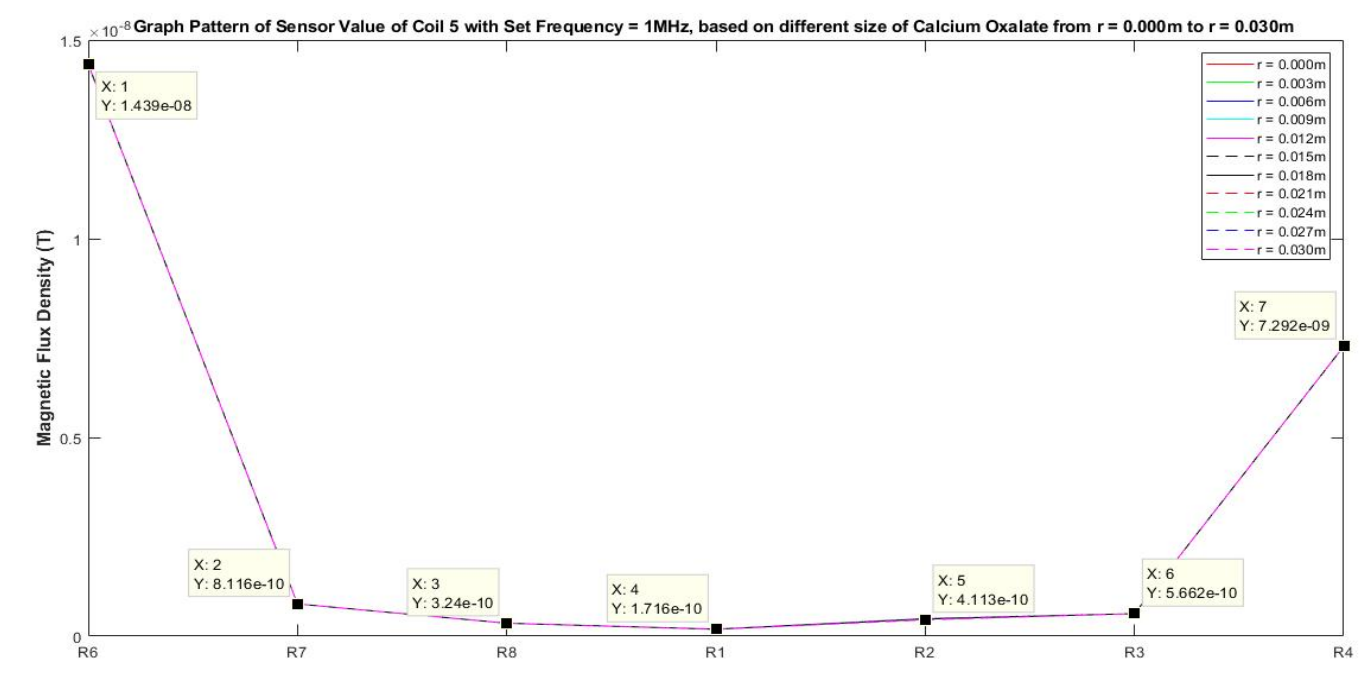

Figure 7 Graph of sensitivity performance at excitation coil 3 , with radius of $0.018 \mathrm{~m}$ of calcium oxalate

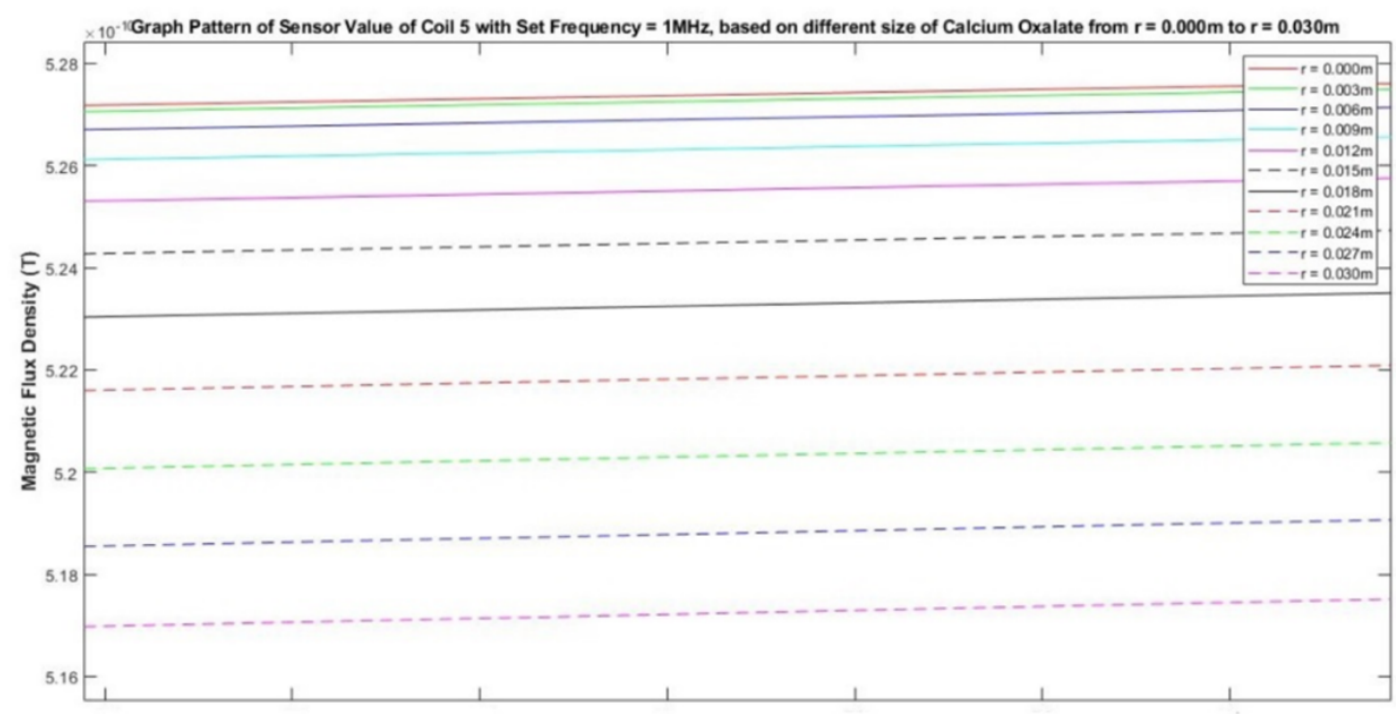

Figure 8 Graph of sensitivity performance at excitation coil 5, with frequency of $1 \mathrm{MHz}$ (magnified) 


\section{Conclusions}

Despite the status of ongoing research in MIT, this technique appears to have the potential in currentradiation base imaging due to its superior advantage as a contactless and non-radioactive imaging technique. This research found out that system frequency and radius of calcium oxalate have an inverse relationship with the sensitivity performance of magnetic induction tomography (MIT) system. Theoretically, higher system frequency would yield higher sensitivity value and performance of MIT. This research proved that $\beta$-dispersion range below $1 \mathrm{MHz}$ is the appropriate measurement range as many pathological processes are reflected within this range. Other than that, all sensitivity performance graphs exhibit a U-shape pattern, where both neighbouring coils from the exciting coil show the highest sensitivity values. It is also crucial to highlight the importance of setting up the correct geometry and parameter to closely imitates the real environment of a kidney for simulation due to each's distinctive passive electrical properties (PEP), especially conductivity value, which gives a significant impact on the result.

\section{Acknowledgement}

This research is being supported and funded by Universiti Teknologi Malaysia research transdisciplinary grant 29.2(T1) Q.J130000.3551.06G17, UTMSHINE Q.J130000.2451.09G18, FRGS K074 and FRGS R.J130000.7851.5F165

\section{References}

[1] A.Z. Middelheim, Antwerp B. Istoria tomografiei. J Belge Radiol. "Dienst Radiologie", 78(5):284-8, 1995. Available from: https://www.ncbi.nlm.nih.gov/pubmed/8550391

[2] Nouri Al, Hassali MA. "Assessment of kidney stone disease prevalence in a teaching hospital". African J Urol, 24(3):180-5, 2018. Available from: https://doi.org/10.1016/j.afju.2018.05.003

[3] Sreenevasan G. "Urinary stones in Malaysia--its incidence and management". Med J Malaysia, 45(2):92-112, 1990.

[4] Scales CD, Smith AC, Hanley JM, Saigal CS. "Prevalence of kidney stones in the United States". Eur Urol. 62(1):160-5, 2012.

[5] Chen Z, Prosperi M, Bird VY. "Prevalence of kidney stones in the USA: The National Health and Nutrition Evaluation Survey". J Clin Urol, 12(4):296-302, 2019.

[6] Power SP, Moloney F, Twomey M, James K, O'Connor OJ, Maher MM. "Computed tomography and patient risk: Facts, perceptions and uncertainties". World J Radiol, 8(12):902, 2016.

[7] Genc A, Ryk M, Suwała M, Żurakowska T, Kosiak W. "Ultrasound imaging in the general practitioner's office". J Ultrason, 16(64):78-86, 2016.

[8] Oldendorf W. "Advantages and Disadvantages of MRI. In: Basics of Magnetic Resonance Imaging". Springer US, p. 125-38, 1988.

[9] Wei HY, Soleimani M. "Hardware and software design for a National Instrument-based magnetic induction tomography system for prospective biomedical applications". Physiol Meas, 33(5):863-79, 2012.

[10] Zakaria Z, Rahim RA, Saiful M, Mansor B, Yaacob S, Muzakkir N, et al. "Advancements in Transmitters and Sensors for Biological Tissue Imaging in Magnetic Induction Tomography", 7126-56, 2012.

[11] Sahlan S, Abdul Sahib MF, A. Danapalasingam K, Abas KH, Abdul Rahim R, Ishak MHI, et al. "Magnetic Induction Tomography: A Brief Review". J Teknologi, 73(3):91-5, 2015.

[12] Hintermüller $M$, Laurain A, Yousept I. "Shape sensitivities for an inverse problem in magnetic induction tomography based on the eddy current model. Inverse Problem", 31(6), 2015.

[13] Darrer BJ, Watson JC, Bartlett P, Renzoni F. "Toward an automated setup for magnetic induction tomography". IEEE Trans Magn, 51(1):1-4, 2015.

[14] Zakaria Z, Hussin MH Bin, Rahim RA, Mohammad NF, Abdullah AA, Yaacob S, et al. "Performance comparisons of new excitation coil design aspects in Magnetic Induction Tomography (MIT) applications". Proc - 2011 2nd Int Conf Intell Syst Model Simulation, ISMS 2011, 400-3, 2011.

[15] Wang L, Al-Jumaily AM. "Imaging of Lung Structure Using Holographic Electromagnetic Induction". IEEE Access, 5(c), 2017.

[16] Zakaria Z, Suki H, Talib MTM, Balkhis I, Ibrahim M, Mansor MSB, et al. "Sensitivity maps reconstruction for magnetic induction tomography modality using experimental technique". J Teknol, 77(17):63-7, 2015.

[17] Saiful M, Mansor B, Jumaah MF, Zakaria Z, Rahim RA, Nor NM, et al. "Sensors \& Transducers Magnetic 
Induction Tomography Modeling in Biological Tissue Imaging Using Two-Port Network Technique", 150(3):1129, 2013.

[18] Deans C, Marmugi L, Hussain S, Renzoni F. "Optical atomic magnetometry for magnetic induction tomography of the heart", 9900:1-10, 2016. Available from: http://arxiv.org/abs/1605.00839\%0Ahttp://dx.doi.org/10.1117/12.2227538

[19] Griffiths H. "Magnetic Induction Tomography System". Meas Sci Technol, 12, 1126, 2001

[20] Wang J, Wang X, Yang D, Wang K, Zhou Y. "Magnetic Induction Tomography Simulation Analysis Based on Comsol Multiphysics Soft". IOP Conf Ser Mater Sci Eng, 394(4), 2018.

[21] H. J. Luo, W. He, Z. Xu L.L. "Preliminary Results on Brain Monitoring of Meningitis Using 16 Channels Magnetic Induction Tomography Measurement System". Prog Electromagn Res, 57-68, 2012.

[22] Stawicki K, Szuflitowska B, Ziolkowski M. "Recent simulation results of the magnetic induction tomography forward problem". Arch Electr Eng, 65(2):327-36, 2016.

[23] He W, Luo H, Xu Z, Wang J. "Multi-channel magnetic induction tomography measurement system". Proc - 2010 $3^{\text {rd }}$ Int Conf Biomed Eng Informatics, BMEI, 1(Bmei):402-5, 2010.

[24] Zakaria Z, Badri Mansor MS, Abdul Rahim R, Balkhis I, Fazalul Rahiman MH, Nor Ayob NM, et al. "Magnetic induction tomography: Receiver circuit and its design criteria". J Teknol (Sciences Eng.), 64(5):83-7, 2013.

[25] Zhang Z, Liu P, Zhou D, Zhang L, Lei H. "Simulation study for a new magnetic induction tomography coil system with weakly perturbing in conducting background". 2014 36th Annu Int Conf IEEE Eng Med Biol Soc EMBC 2014, (1):1127-30, 2014.

[26] Caeiros JMS, Martins RC. "An optimized forward problem solver for the complete characterization of the electromagnetic properties of biological tissues in magnetic induction tomography". IEEE Trans Magn, 48(12):4707-12, 2012.

[27] "Tissue Frequency Chart" » IT'IS Foundation [Internet]. [cited 2020 July 8]. Available from: https://itis.swiss/virtual-population/tissue-properties/database/tissue-frequency-chart/

[28] "Dielectric Properties of Body Tissues": HTML clients [Internet]. [cited 2020 July 8]. Available from: http://niremf.ifac.cnr.it/tissprop/htmlclie/htmlclie.php

[29] "EC Formula - Depth" [Internet]. [cited 2020 July 8]. Available from: https://www.nde-ed.org/GeneralResources/ Formula/ECFormula/DepthofPenetration/ECDepth.htm

[30] Ali ARM, Raj NAN. "Dielectric behavior of calcium oxalate monohydrate urinary stone". Adv Mater Res, 584:499-503, 2012.

[31] Gowry, B., Shahriman, A. B., \& Zulkarnay, Z. "A new 2D magnetic induction tomography system for phantom detection and localization in medical applications". International Journal of Mechanical and Mechatronics Engineering, 16(4), 103-112, 2016.

[32] Scharfetter, H., Lackner, H. K., Rosell, J. "Magnetic induction tomography: Hardware for multi-frequency measurements in biological tissues". Physiological Measurement, 22(1), 131-146, 2001.

[33] García-Martín J, Gómez-Gil J, Vázquez-Sánchez E. "Non-destructive techniques based on eddy current testing". Sensors, 11(3):2525-65, 2011. 